\title{
Correspondence
}

\section{Epidural Morphine for Analgesia After Caesarean Section}

To the Editor:

In a recent study of epidural morphine after Caesarean section Carmichael et al. conclude that 'This technique of pain management is reliable and safe using a $4 \mathrm{mg}$ dose ... . Our experience suggests that patients would be adequately monitored postpartum on the ward if vital signs were taken hourly for the first 8 to 12 hours after each epidural dose of morphine."

Only 29 patients were studied, ten receiving morphine $4 \mathrm{mg}$ epidurally. Respiratory rate was the only way of monitoring the ventilation and blood gases were not checked in the group receiving morphine $4 \mathrm{mg}$.

Rare, but serious late respiratory depression has been a major problem in epidural morphine analgesia, ${ }^{2-5}$ a fact which was stressed in your epidural 'Déjà Vu' less than a year ago. ${ }^{6}$ In the same volume Knill et $a l^{7}$ showed that epidural morphine changed the respiratory pattem in healthy individuals, and that ventilatory depression primarily was due to reductions in tidal volume.

Accordingly I question the appropriateness of a general statement such as the one cited above, based upon the study reported. Carmichael's recommendation to keep these patients in ordinary obstetric wards may sooner or later bring about serious or even catastrophic consequences. Patients receiving epidural morphine would be safer in intensive care units.

Per Egil Haavik, MD

Department of Anesthesiology, Ullevål Hospital University of Oslo

Oslo, Norway

\author{
REFERENCES \\ 1 Carmichael FJ, Rolbin SH, Hew EM. Epidural
}

Morphine for analgesia after Caesarean section. Can Anaesth Soc J 1982; 29: 359-63.

2 Glynn Cl, Mather LE, Cousins MJ, Wilson PR, Graham JR. Spinal narcotics and respiratory depression. Lancet 1979; 2: 356-7.

3 Davies GK, Tolhurst-Gleaver CL, James TL. CNS depression from intrathecal morhine. Anesthesiology 1980; 52: 280.

4 Christensen $V$. Respiratory depression aftcr cxtradural morphine. Br J Anaesth 1980; 52: 841

5 Reiz $S$, Westberg $M$. Side effects of epidural norphine. Lancet 1980; 2; 203-4.

6 Wyant GM. Déjà Vu. Editorial. Can Anaesth Soc J 1981; 28: 551-2.

7 Knill RL, Clement $J L$, Thompson WR. Epidural Morphine Causes delayed and prolonged ventilatory depression. Can Anaesth Soc J 1981; 28: 537-43.

\section{$R E P L Y$}

Thank you for the invitation to reply to Dr. Haavik' sietter concerning our article 'Epidural Morphine for Analgesia after Caesarean Section' published in the July 1982 issue of the Journal.

Our study was a randomized double blind placebo controlled study of efficacy, duration and safety of epidural morphine for the management of postcaesarean section pain. Dr. Haavik is concerned, as indeed we are. about the safety of this technique. To date, epidural morphine administration to more thant 8,000 patients has been reported. One recent survey of practice in Sweden ${ }^{I}$ reported respiratory depression in 23 patients out of 6,000 who received epidural morphine. Delayed respiratory depression afier epidural narcotics is more frequent if the patient is elderly, debilitated, has impaired respiratory functions or has received both epidural and systemic opiates. All of the case reports referred to by $D r$. Haavik are in this category except possibly the case reported by Reiz and Westburg ${ }^{2}$ who unfortunasely did not state the age of their patient. We are not aware of any case reports of delayed respiratory depression in young healthy patients following epidural morphine in acceptable doses (e.g. less than $5 \mathrm{mg}$ ).

The investigations by Knill et al were done in normal healthy individuals who had not undergone surgery. Postoperative patients receiving epidural morphine need to be compared to those receiving parenteral morphine. The clinical applicability of such studies is more obvious. Lastly, we are not recommending the use of epidural 